\title{
In memoriam: Professor Akira Ochiai (1923-2017)
}

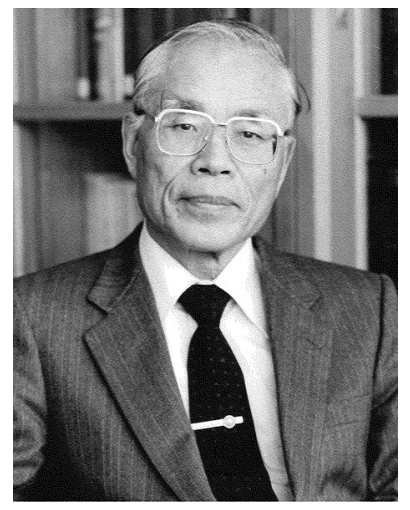

Professor Akira Ochiai, an Honorary Member of the Japanese Society of Fisheries Science and Professor Emeritus at Kochi University, passed away on 30 December 2017 at the age of 95.

Professor Ochiai was born in Mie Prefecture on 14 September 1923. He graduated from Kyoto University in 1950, and was hired as an assistant professor in the same year. Thereafter, he held several positions within the Department of Fisheries, Faculty of Agriculture of Kyoto University. He specialized in the field of fish biology and conducted phylogenetic and systematic studies of fish species under the leadership of Dr. K. Matsubara, Senior Professor at Kyoto University.

His doctoral dissertation was on the systematic, anatomical and phylogenetic study of soleoid fishes of the Pleuronectiformes order distributed in coastal areas of southern Japan in the Pacific Ocean. Part of the dissertation was published in Copeia, a renowned American ichthyological magazine, and the whole work was later published in a book titled Fauna Japonica.

In 1965, he moved to Kochi University where a new department of Aquaculture and Stock Enhancement was established. He was appointed as professor of the Laboratory of Aquaculture Science, where he led his staff including
Associate Professor Dr. R. Kusuda, and Assistant Profs. Mr. S. Umeda and Dr. N. Taniguchi. His laboratory covered such fields of study as fish ecology, fish stock enhancement, fish seed production, fish disease management, fish breeding science, aquaculture biotechnology, and fish genetics.

At Kochi University, Professor Ochiai enthusiastically engaged in educational activities for both Japanese and foreign students, and actively gave them opportunities to become involved in the latest research and technological topics. As a result, they were employed in diverse occupations in the aquaculture and fisheries industries, and as public officials of the national and local governments.

Professor Ochiai's scientific contributions included 21 technical books, 73 scientific papers, 44 reviews, and 10 reports in his major fields based on experimental and laboratory work.

He also contributed extensively to the Japanese Society of Fisheries Science (JSFS), serving as a member of the directors and councillors for many years. In 1986, he received the Award of the Japanese Society of Fisheries Science, Merit in the field of Fish ecology and fish systematics.

In 2000, he also received The Order of the Rising Sun, Gold Rays with Neck Ribbon. In 2018, he was awarded the court rank of Shoshii (senior forth rank) through the government.

We would like to express our deepest sorrow at the departure of Professor Akira Ochiai and offer our condolences to his family. He made significant achievements in the field of fisheries science and ichthyology, and trained many talented individuals who are currently working in academia, government and industry.

Nobuhiko Taniguchi

Emeritus Professor, Kochi University Emeritus Professor, Tohoku University. 